\title{
A numerical model for river habitat restoration: a case study of the Chin-sha River in China
}

\author{
Yao W..$^{1,2,3^{*}}$, Chen Y. ${ }^{2}$ and Ma X..$^{3,4}$ \\ 1State Key Laboratory of Hydraulic Engineering Simulation and Safety, Tianjin University, Tianjing, 300072, China \\ ${ }^{2}$ Key Laboratory of Environmental Remediation, Institute of Geographic Sciences and Natural Resources Research, China Academy of \\ Sciences, Beijing, 100101, China \\ ${ }^{3}$ Department of Water Resources and Architectural Engineering, Northwest A\&F University, Yangling 712100, China \\ ${ }^{4}$ Key Laboratory for Agricultural Soil and Water Engineering in Arid Area of Ministry of Education, Northwest A\&F University, Yangling, \\ Shaanxi Province 712100, China \\ Received: 21/03/2018, Accepted: 26/04/2019, Available online: 06/05/2019 \\ *to whom all correspondence should be addressed: e-mail: science_research@126.com \\ https://doi.org/10.30955/gnj.002691
}

\begin{abstract}
Currently, the ecosystem is being damaged in many rivers and subsequently the fish species living there are also facing decline or even extinction. This situation urges to model the habitat and to design suitable restoration strategies in order to increase the capabilities of ecological modeling. In this paper, we proposed a numerical model to assess the ecosystem habitat situation and investigated the impacts of two ecological restorations strategies for the target fish species. The model includes a hydrodynamic model, a habitat model and habitat restoration schemes. The hydrodynamic model simulated the flow properties while sediments in the riverbed were also surveyed. Based on these parameters and fish preference curves, the habitat suitability indices were calculated. In order to analyze the river habitat quality, the weighted usable areas and overall suitability index were also calculated and the effects of the restoration strategies on selected fish species (Freshwater Reeves shad - Tenualosa reevesii) in the Chin-sha River were evaluated. The two ecological restoration strategies: addition of side-channel (Scheme I) and riverbank reconstruction (Scheme II) enhanced the Freshwater Reeves shad habitat suitability level, with the high suitability index proportion increasing from $19.5 \%$ to $33.1 \%$ for Scheme I and to $36.1 \%$ for Scheme II. Based on the modelling results, we concluded that our numerical model could potentially provide suitable scenarios for successful fish habitat restoration.
\end{abstract}

Keywords: River restoration strategy, ecohydraulic simulation, Chin-sha River, habitat suitability, side-channel, riverbank reconstruction.

\section{Introduction}

It is well established that aquatic ecosystems of rivers and streams are linked by physical processes at spatial and temporal scales. Habitat modelling has incorporated hydrodynamics and a large number and wide variety of eco-hydrodynamic models developed over the last decades are indicating a strong interest in river and habitat restoration (Rutschmann et al., 2014; Yao et al., 2014a, 2017; Frainer et al., 2018). The scientific interest in understanding fundamental processes in the river and habitat restoration can be traced back to 1980 s when the physical habitat models were used as important tools for river management (Bovee, 1982; Bovee, 1986). Another importance of eco-hydrodynamic models is to be used as predictive tools supporting inter-disciplinary ecosystem management and predicting the effectiveness of river restoration schemes (Yao et al., 2014; 2017a, b). The decline or extinction of aquatic species has raised great interest in habitat restoration. Therefore, it is important to use numerical models in order to assess the impact of habitat suitability levels and restoration strategies.

The river and habitat restoration is an attempt to recoup some of the ecosystem services which are being lost in the recent past. To achieve this, a more long-term effective and economical way is to use technological fixes such as sewage or sludge treatment plants (Palmer et al., 2007). Currently, to restore river ecosystems, restoration strategies and planning projects are in progress. Examples include, the United States have spent a large sum of financial resources on the restoration of aquatic habitats and many endangered species (Bernhardt et al., 2005; Yao et al., 2015). Since 2010, China has implemented most strict water management rules to protect and restore river ecosystems (Chen, 2007). Australia, on the other hand, has completed more than 2,200 stream restoration projects which include riparian management projects, bank stabilization, in-stream habitat improvement, and habitat monitoring projects (Brooks and Lake, 2007). In all successful and effective stream restorations, hydrodynamic and riverbed substrates survey are the key factors (Bond and Lake, 
2003; Wang and Lin, 2013). Thus, to provide a scientific basis for effective stream restoration, it is important to link the hydrodynamic and substrates characteristics of the stream system to a habitat model and subsequently to evaluate and improve the levels of stream systems using an integrated eco-hydraulic model.

In order to examine relations between restoration schemes, and habitat improvement, we evaluated the current habitat suitability level and investigated two river restoration strategies, namely, addition of side-channel (Scheme I) and riverbank reconstruction (Scheme II). The Chin-sha River and the Freshwater Reeves shad (Tenualosa reevesii) were selected to study river and target fish restoration by the local Water Conservancy Bureau for restoration. We utilize measured hydrological and topographical data as a current condition to simulate the water velocity and depth for the study domain. We then used these results and surveyed substrates to calculate the fish habitat quality. The habitat conditions for the Freshwater Reeves shad were also quantified by combining hydrodynamic models and the fish suitability index.

\section{Problem definition and modeling}

\subsection{Study area}

We proposed the eco-hydraulic model on the Chin-sha River, which has a length of $564 \mathrm{~km}$ with eight hydraulic power stations namely, the Longpan, the Two family, the Pear, the Areva, the Jin'anqiao, the Longkaikou, the Ludila and the Guanyinyan. The Chin-sha River basin is stretched from the Sichuan Province to the Yunnan province. The abundant water resources in the Chin-sha River play a vital role for the sustainability of the ecological system of approximately 25 fish species living there. The ecohydraulic model used in this study is a $9.4 \mathrm{~km}$ long river reach located between the Pear and the Areva power stations (Figure 1). The width of the river reach is ranged from 438 to $923 \mathrm{~m}$ and the maximum river depth are $4.94 \mathrm{~m}$. The model data of the river obtained by field survey and interpolation. As the domain is a natural spawning site with high ecological requirement for the fish species living there, the effects of restoration strategies need to be investigated. The Freshwater Reeves shad was selected as target fish species to test the restoration strategies. The preference curves of the spawning Freshwater Reeves shad are shown in Figure 2 which are based on literature review and field work.

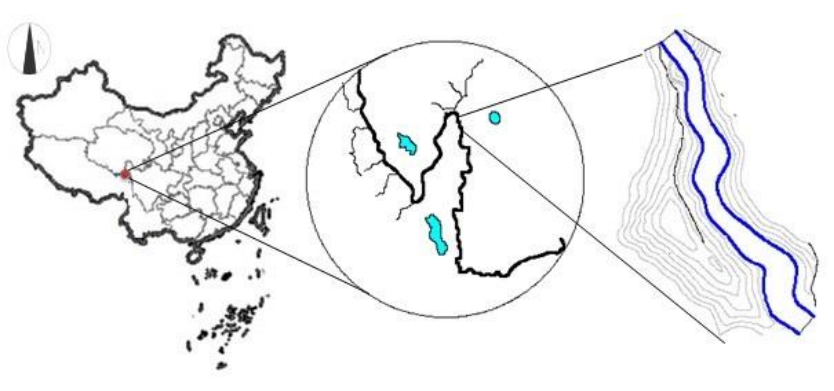

Figure 1. The Chin-sha River location and the computational domain
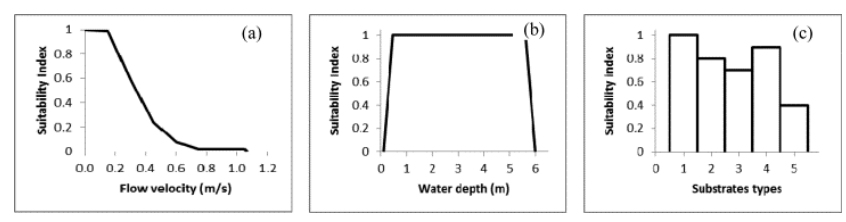

Figure 2. Suitability index of freshwater Reeves shad (Tenualosa reevesii): a) effect of velocity, b) effect of water depth, c) effect of substrate type ( 1 = clay; 2 = sand; $3=$ cobbles; 4 = gravel; $5=$ boulders)

\subsection{Mathematical modelling}

The numerical model consists of three parts; (1) a hydrodynamic model with riverbed substrates survey, (2) a habitat model, and (3) restoration strategies evaluation. For the hydrodynamic model, three assumptions were made; the Boussinesq approximation, the eddy viscosity concept, and the shallow water (Yao, 2016).

\subsubsection{Hydrodynamic model}

Continuity equation

$u \frac{\partial h}{\partial x}+v \frac{\partial h}{\partial y}=0$

Momentum equation

$$
\begin{aligned}
& u \frac{\partial u}{\partial x}+v \frac{\partial u}{\partial y}=-g \frac{\partial \eta}{\partial x}+\frac{1}{h}\left(\frac{\partial h \chi_{u}}{\partial x}+\frac{\partial h \chi_{u}}{\partial y}\right) \\
& u \frac{\partial v}{\partial x}+v \frac{\partial v}{\partial y}=-g \frac{\partial \eta}{\partial y}+\frac{1}{h}\left(\frac{\partial h \chi_{v}}{\partial x}+\frac{\partial h \chi_{v}}{\partial y}\right)
\end{aligned}
$$

where $x$ and $y$ are the two horizontal coordinates; $u, v$ are the velocity in the $\mathrm{x}$ and $\mathrm{y}$ directions, respectively; $\eta$ is the water surface elevation; $h$ is water depth; $\chi_{u}$ and $\chi_{v}$ stand for the depth integrated Reynolds stresses which are calculated by using the $k-\varepsilon$ turbulence model.

The $k-\varepsilon$ model is an empirical model, which contains the turbulence kinetic energy $(k)$ and its dissipation rate $(\varepsilon)$.

Turbulent kinetic energy equation

$u \frac{\partial k}{\partial x}+v \frac{\partial k}{\partial y}=\frac{\partial}{\partial x}\left(\chi_{k} \frac{\partial k}{\partial x}\right)+\frac{\partial}{\partial y}\left(\chi_{k} \frac{\partial k}{\partial y}\right)-\varepsilon-G_{b}+G_{k}$

Turbulent dissipation rate equation

$u \frac{\partial \varepsilon}{\partial x}+v \frac{\partial \varepsilon}{\partial y}=\frac{\partial}{\partial x}\left(\chi_{\varepsilon} \frac{\partial \varepsilon}{\partial x}\right)+\frac{\partial}{\partial y}\left(\chi_{\varepsilon} \frac{\partial \varepsilon}{\partial y}\right)-\frac{C_{2} \varepsilon^{2}}{k}-C_{1} C_{3} G_{b} \frac{\varepsilon}{k}+C_{1} \frac{\varepsilon}{k} G_{k}$

where $\chi_{k}$ and $\chi_{\varepsilon}$ are diffusion coefficients; $G_{k}$ and $G_{b}$ are terms of turbulent kinetic energy generation by mean shear and buoyancy, respectively; $C_{1}, C_{2}$, and $C_{3}$ are constants of the model; where the other parameters are the same as previous.

\subsubsection{River bed survey}

According to the river bathymetric survey sampling and subsequent interpretation, five types of sediments dominate in the study area; clay, sand, gravel, cobbles, and boulders. The sediments distribution of the riverbed and its suitability index are shown in Figure 3. 

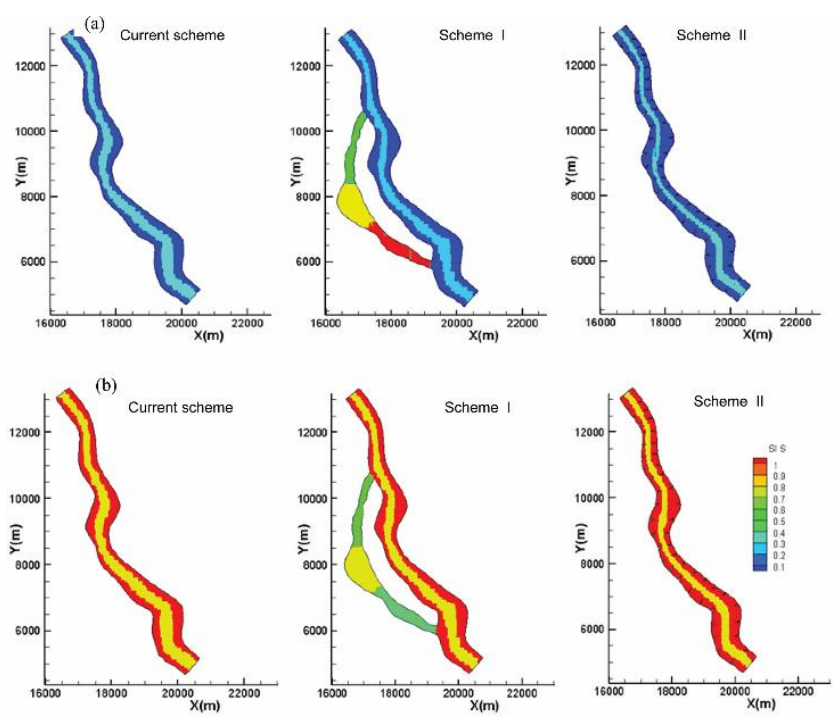

Figure 3. River bed substrate types (a) and the Freshwater Reeves shad suitability index (b) for the five substrate types (SI S = suitability index of substrates $).(\square=$ clay; $\square=$ sand; $\square=$ cobbles; $\square$ = gravel; = boulders)

\subsubsection{Habitat model}

Based on preference suitability curves, water velocity and depth, and substrates were selected as variables for the calculation of the habitat suitability index. The habitat suitability index (HSI), the weighted usable area (WUA) and overall suitability index (OSI) were calculated. The values of $\mathrm{HSI}$ ranged from 0 to 1 , with 0 for the lowest and 1 for the highest suitability.

$$
\begin{aligned}
& H S I=\left(S I_{v} \times S I_{d} \times S I_{s}\right)^{1 / 3} \\
& W U A=\sum_{i=1}^{M} A_{i} \times H S I_{i, t} \\
& \text { OSI }=\frac{\sum_{i=1}^{M} A_{i} \times H S I_{i}}{\sum_{i=1}^{M} A_{i}} \times 100 \%
\end{aligned}
$$

where $M$ is the total number of grid meshes; $A_{i}$ is the area of the single mesh; $S I_{v}$ is the suitability index of water velocity; $S I_{d}$ is the suitability index of water depth; and $S I_{s}$ is the suitability index of substrates. The index HSI is categorized as low (0-0.3), moderate $(0.3-0.7)$ and high (0.7-1.0).

\subsubsection{Habitat restoration strategies and model setup}

We evaluated three habitat suitability schemes: current scheme, addition of a side-channel (Scheme I), and river bank reconstruction (Scheme II) (Figure 4). To solve the partial differential equations, the finite volume method was used in all three numerical model applications. Three types of boundary conditions, inlet, outlet and solid boundary, were applied in the model. The convergence, which is based on the maximum errors in global mass and energy balances, was ensured using maximum errors less than $10^{-9}$ criteria in order to guarantee the high accuracy of the numerical model (Yao et al., 2014). A systematic grid independence study was conducted for the model setup. The final grid nodes were 11,055 for the current scheme, 14,780 for Scheme I and 10,784 for Scheme II. The grid sizes were 21,190, 28,173 and 20,008, respectively. The numerical model setup was integrated a hydrodynamic, habitat and habitat restoration module. The hydrodynamic codes were obtained from open source software Telemac2d (Hervouet, 2000), while the habitat and habitat restoration module were developed by the authors.
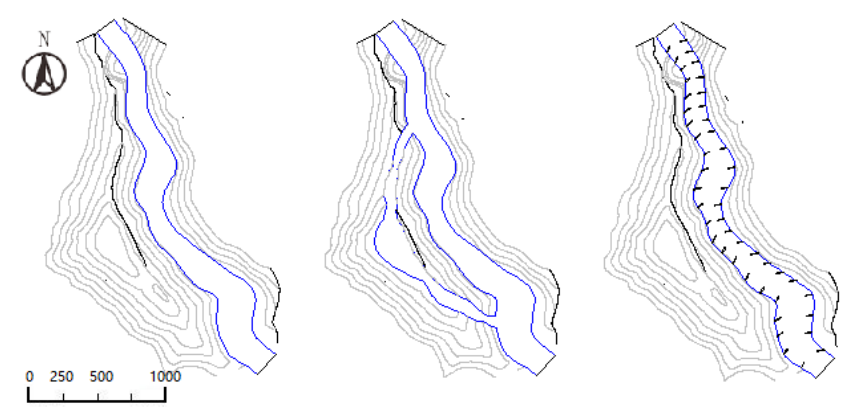

Figure 4. Current scheme, restoration Scheme I, and restoration Scheme II for the computational domain in the Chin-sha River, China

\section{Results and discussion}

The numerical model was applied to assess the habitat qualities of the current scheme and two restoration schemes (Scheme I, and Scheme II). Based on the values of water depth and velocity, and substrates, the habitat suitability index distributions were calculated as shown in Figure 5. Habitat sensitivity and comparison of the three schemes was also performed.

\subsection{Current scheme}

The Freshwater Reeves shad habitat suitability index distribution at current scheme is shown in Figure 5. It is noted that the Chin-Sha River branch would not be suitable for the Freshwater Reeves shad. Most of the river branches have low HSI values with only the downstream near-shore and backwater nursery areas, which provide suitable habitat conditions for refuge and nursing areas. The percentages of the high, moderate and the low habitat suitability for the Freshwater Reeves shad are $19.5 \%, 3.9 \%$ and $76.6 \%$, respectively (Table 1 ). The corresponding areas for the high, moderate and low habitat suitability are 1.2 million $\mathrm{m}^{2}, 0.24$ million $\mathrm{m}^{2}$ and 4.6 million $\mathrm{m}^{2}$. The WUA and OSI for the Freshwater Reeves shad in the Chin-sha River are 1.55 million $\mathrm{m}^{2}$ and $25.6 \%$, respectively.

Table 1. Comparison of the HSI distribution in the Chin-sha River

\begin{tabular}{cccc}
\hline & Current (\%) & Scheme I (\%) & Scheme II (\%) \\
\hline Low & 76.6 & 62.0 & 59.9 \\
\hline Moderate & 3.9 & 4.9 & 4.0 \\
\hline High & 19.5 & 33.1 & 36.1 \\
\hline
\end{tabular}



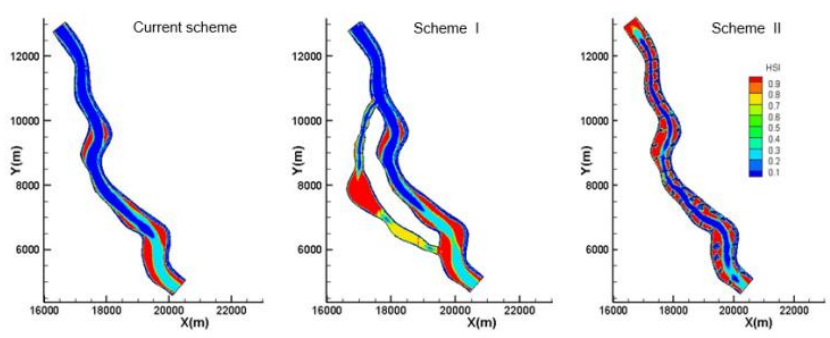

Figure 5. Habitat suitability index distributions of Freshwater reeves shad (Tenualosa reevesii) under current scheme, restoration Scheme I and Scheme II

\subsection{Scheme I: addition of side-channel}

The suitability index distribution for Scheme I (addition of side-channel) was calculated and it is also shown in Figure 5. Comparing with the current scheme, it is noted that the habitat level in the main stream of the study area was improved. It is also noted that the habitat suitability level in most areas of side-channel were high. Comparison with the current scheme's habitat condition shows that the percentage of the low and moderate habitat suitability for the Freshwater Reeves shad decreased to $62 \%$ and $4.9 \%$, while the high habitat suitability increased from $19.5 \%$ to $33.1 \%$. The WUA and OSI were increased to 3.1 million $\mathrm{m}^{2}$ and $37.5 \%$, respectively which is significantly higher than that of corresponding value at current scheme.

\subsection{Scheme II: addition of side-channel}

Scheme II (the riverbank reconstruction) were also performed. It is clearly shown that in overall, the fish habitat conditions were significantly improved along the river bank of the Chin-sha River, except in the middle of the river areas. In Scheme II, the proportions of the high, moderate and low habitat suitability for the Freshwater Reeves shad are $36.1 \%, 4.0 \%$, and $59.9 \%$, respectively. The corresponding WUA and OSI values are 2.4 million $\mathrm{m}^{2}$ and $41.2 \%$, respectively.

\subsection{Comparison of restoration schemes}

A comparison of the habitat conditions (between the two restoration schemes and the current condition) showed that the values of the WUA, OSI and the high habitat suitable areas for the restoration strategies, namely, Scheme I and Scheme II are much higher than the current condition. According to the values of highly suitable areas, the restoration strategy of Scheme II is better than that of Scheme I.

Although, evaluating the river restoration strategies also rely on both the pre and post-monitoring data, this data of the Chin-sha River at current stage has hampered progress in practical understanding of the physical processes. However, as numerical modelling has successful improved the river restorations (Zhang et al., 2016, 2016a; Yao et al., 2018), the overall accuracy and performance of our numerical model gives confidence in the numerical model.

\section{Conclusions}

In this study, a numerical model was proposed to investigate the Freshwater Reeves shad habitat suitability and two restoration strategies in the Chin-sha River. We evaluated the habitat and ecological situation on three different scales and assessed the habitat situation improvement for two proposed restoration schemes. We have emphasized the importance of the river restoration strategies, which can improve the physicalspecies-habitat relationships in the field. With the numerical modelling, the ecological status and the available knowledge on the habitat parameters were considered. The numerical model also potentially provided suitable scenarios for successful fish habitat restoration. Although our study is specific for the Chin-sha River and can also be used to evaluate habitat conditions in other cases.

\section{Conflict of Interest}

The authors declare no conflict of interest.

\section{Acknowledgments}

This study was supported by the National Key R\&D Program of China (2016YFC0502004), the SKL of HESS-1803, CCA project (2017.07), project (2017YFC0404304), project (2016AG003), and China national research funding (41430861).

\section{References}

Bernhardt E.S., Palmer M., Allan J.D., Alexander G., Barnas K., Brooks S., Carr J., Clayton S., Dahm C., Follstad-Shah J., Galat D., Gloss S., Goodwin P., Hart D., Hassett B., Jenkinson R., Katz S., Kondolf G.M., Lake P.S., Lave R., Meyer J.L., O'Donnell T.K., Pagano L., Powell B. and Sudduth E. (2005), Synthesizing U.S. river restoration efforts. Science (Washington), 308(5722), 636-637.

Bond N.R. and Lake P.S. (2003), Local habitat restoration in streams: constraints on the effectiveness of restoration for stream biota. Ecological Management \& Restoration, 4(3), 193-198.

Bovee K.D. (1982), A Guide to Stream Habitat Analysis Using the Instream Flow Incremental Methodology. Instream Flow Information Paper No. 12 US Fish and Wildlife Service, Fort Collins, Colorado 248, pp. 56.

Bovee K.D. (1986), Development and evaluation of habitat suitability criteria for use in the instream flow incremental methodology. Instream flow information paper no. 21, US Fish and Wildlife Service Biological Report, Washington, DC, 86(7).

Brooks S.S. and Lake P.S. (2007), River restoration in Victoria, Australia: change is in the wind, and none too soon. Restoration Ecology, 15(3), 584-591.

Chen L. (2007), Implement the most stringent water management system to protect the economic and social sustainable development. Peoples Forum, 6, 10-12 (In Chinese).

Frainer A., Polvi L.E., Jansson R. and McKie B.G. (2018), Enhanced ecosystem functioning following stream restoration: the roles of habitat heterogeneity and invertebrate species traits. Journal of Applied Ecology, 55(1), 377-385. 
Hervouet J.M. (2000), TELEMAC modelling system: an overview. Hydrological processes, 14(13), 2209-2210.

Palmer M., Allan J.D., Meyer J. and Bernhardt E.S. (2007), River restoration in the twenty-first century: data and experiential knowledge to inform future efforts. Restoration Ecology, 15(3), 472-481.

Rutschmann P., Bui M.D., Abdelaziz S., Yao W., Rutschmann B. and Geiger F. (2014), "Ökologische Modellierungen-drei Fallbeispiele", Drei $\quad 37$. www.swv.ch/Symposium-AGAW-2013.

Wang F. and Lin B. (2013), Modelling habitat suitability for fish in the fluvial and lacustrine regions of a new Eco-City. Ecological Modelling, 267, 115-126.

Yao W., Chen Y., Zhong Y., Zhang W. and Fan H. (2017), Habitat models for assessing river ecosystems and their application to the development of river restoration strategies. Journal of Freshwater Ecology, 32(1), 601-617.

Yao W., Rutschmann P. and Bamal S. (2014), Modeling of river velocity, temperature, bed deformation and its effects on rainbow trout (Oncorhynchus mykiss) habitat in Lees Ferry, Colorado River". International Journal of Environmental Research, 8(4), 887-896.

Yao W., Zhao T., Chen Y., Zhong Y., Fan H., Zhang W. and Li L. (2017a), Habitat evaluation model for ecologically successful lake restoration. Lake and Reservoir Management, 33(3), 301-313.

Yao W., Liu H., Chen Y., Zhang W., Zhong Y. Fan H. and Bamal S. (2017b), Simulating Spawning and Juvenile Rainbow Trout (Oncorhynchus mykiss) Habitat in Colorado River Based on High-Flow Effects. Water, 9(2), 150.

Yao W., Kumar V. and Rutschmann P. (2014a), Simulating dam effects on river deformation and rainbow trout (Oncorhynchus mykiss) population number. River Flow, 2471-2477.

Yao W., Rutschmann P. and Sudeep. (2015), Three high flow experiment releases from Glen Canyon Dam on rainbow trout and flannelmouth sucker habitat in Colorado River. Ecological Engineering, 75, 278-290.

Yao W. (2016), Application of the ecohydraulic model on hydraulic and water resources engineering. Munchen, Germany: Technische Universitat Munchen; p. 220. ISBN 978-3-943683-11-0.

Yao W., Bui M.D. and Rutschmann P. (2018), Development of eco-hydraulic model for assessing fish habitat and population status in freshwater ecosystems. Ecohydrology, e1961.

Zhang W., Yao W., Li L. and Zhang Q. (2016), Using an ecohydrodynamic model to simulate the impact of trunk dam construction on Kraal River fish habitat and community. International Journal of Environmental Research, 10(2), 227236.

Zhang W., Di Z., Yao W. and Li L. (2016a), Optimizing the operation of a hydraulic dam for ecological flow requirements of the You-shui River due to a hydropower station construction. Lake and Reservoir Management, 32(1), 1-12. 